\title{
Emerging evidence of superior performance in laparoscopic combined hepatectomy and colectomy
}

\author{
Tan To Cheung ${ }^{1}$, Siolam Un ${ }^{2}$ \\ ${ }^{1}$ Department of Surgery, Queen Mary Hospital, The University of Hong Kong, Hong Kong, China; ${ }^{2}$ Department of Surgery, Kiang Wu Hospital, \\ Macau, China \\ Correspondence to: Tan To Cheung, MBBS, MS, FRCSHK, FHKAM, FCSHK. Chief of Hepatobiliary and Pancreatic Surgery, Associate \\ Professor, Department of Surgery, Queen Mary Hospital, The University of Hong Kong, 102 Pokfulam Road, Hong Kong, China. \\ Email: tantocheung@hotmail.com. \\ Provenance: This is an invited Editorial commissioned by Editor-in-Chief Minhua Zheng (Department of General Surgery, Ruijin Hospital, Shanghai \\ Jiaotong University School of Medicine, Shanghai Minimal Invasive Surgery, Shanghai, China). \\ Comment on: Ratti F, Catena M, Di Palo S, et al. Impact of totally laparoscopic combined management of colorectal cancer with synchronous hepatic \\ metastases on severity of complications: a propensity-score-based analysis. Surg Endosc 2016;30:4934-45.
}

Received: 08 May 2017; Accepted: 17 May 2017; Published: 03 July 2017.

doi: 10.21037/ales.2017.06.02

View this article at: http://dx.doi.org/10.21037/ales.2017.06.02

Laparoscopic liver resection is going to be a standard practice for straight forward cases. Laparoscopic has obvious advantages of rapid recovery and smaller wound. We are now entering an adaptation phase where more challenging indications and technically demanding procedures being ventured. It has been extended to laparoscopic procedures for pancreatic disease involving complex reconstructions, for liver cancer where patients had

severe cirrhosis and combined resection for multiple organs.

Nearly $23 \%$ to $51 \%$ of the 157,000 new colorectal cancer patients will present with synchronous colorectal cancer and liver metastasis (1). Surgical resection of all tumor sites is the only treatment that offers prolonged survival (2-4). Minimally invasive approach for colorectal carcinoma has been an accepted treatment modality for many years. With improvement in surgical techniques, magnification of the camera and display unit, development of designated instrument, laparoscopic colorectal resection can be carried out safely, however, combined liver resection with colorectal cancer has still been considered as high risk operations with expected higher morbidity and even mortality.

Ratti et al. recently reported totally laparoscopic combined management of colorectal cancer with synchronous hepatic metastases on severity of complications in the Surg Endosc (2016) (5). The authors showed that the totally laparoscopic method had lower blood loss (350 vs. $600 \mathrm{~mL}$ ), shorter postoperative stay (9 vs. 12 days), lower postoperative morbidity index $(0.14 v s .0 .20)$, lower severity score for complicated patients $(0.60 v s .0 .85)$, and better rapid functional recovery, had better recurrence- free survival. This study showed that simultaneous colorectal and hepatic resection can be safely performed as a onestep procedure. The beauty of this result encourages the surgeons to perform totally laparoscopic surgery for primary colorectal cancer with synchronous liver metastases.

Since the World Consensus Conference on Laparoscopic Surgery has suggested that acceptable indications for laparoscopic liver resection include solitary lesions of $5 \mathrm{~cm}$ or less, located in limited liver segments. Moreover, major hepatectomy (more than 3 segments) is reported to independently predict severe morbidity after simultaneous resection of CRC (hazard ratio $=3.4, \mathrm{P}=0.008$ ). It is wise for Francesca's group in carefully selecting patients with better risk to performed these combined laparoscopic resections (i.e., tumor size less than $5.0 \mathrm{~cm}$, and up to 3 liver lesions).

"Doing no harm" is the most important concept of surgical treatment. Comparison of immediate outcome had been compared between one-step with two- step resection in various studies (6-9). Some studies have reported no difference in survival $(6,8,9)$, whereas others reported that two-step resection results in better survival (10-12). These studies were small, retrospective, and subject to length-time bias and selection bias, potentially resulting in misleading 
conclusions as to which procedure is better. In previous studies of simultaneous colorectal and hepatic resections, 5 -year survival rates ranged from $20 \%$ to $55 \%$, with a median survival time of 28 to 40 months $(12,13)$. Recently, Weber et al have shown that the median survival time and 5 -year survival rates of patients undergoing one-step liver resection were 35 months and $21 \%$, respectively (8). They concluded that the characteristics of the primary tumor and the presence of synchronous colorectal and liver metastases had no influence on survival after one-step resection. The first question to consider with a synchronous versus staged resection for colorectal tumors with hepatic metastases is the safety of each approach. Vogt et al. was the first to examine the safety of synchronous resection for colorectal cancer (9). The authors compared operative mortality between 19 patients who underwent a synchronous resection to 17 patients who had a staged resection (median 2 months between resections). There were no perioperative deaths in either group. The authors concluded that synchronous resection was associated with a low rate of complication and no operative mortality provided that colorectal resections are not combined with extended liver resections.

So I believed combined liver resection with colorectal cancer underwent laparoscopic procedure can be considered as a safety operation.

The oncological outcomes of simultaneous colorectal and liver resections (SIMR) is vary in different published studies (14-17). The approach was suggested by some authors to be useful in selecting tumors with good biological behavior for the interval hepatic resection. But some authors believe that SIMR should not be totally excluded in the surgical management of CRM with its inherent advantage of complete macroscopic tumor clearance in one single operation and of facilitating timely commencement of adjuvant chemotherapy. Some studies have suggested that major hepatectomy would increase the short-term morbidity with SIMR $(18,19)$ hence resulting in longer hospital stay.

However, patients requiring major liver resection should not be precluded from SIMR, provided that the meticulous operation is performed to ensure low short-term morbidity. Recent review also suggested SIMR should be undertaken in specialized colorectal and hepatobiliary surgery center in order to achieve better results (20).

In summary, the advantages of laparoscopy over open surgery have been highlighted in many series, both in the setting of isolated colorectal and in combination of hepatic resections. The current evidence is emerging but we still need a larger volume multicenter studies, preferably prospective design studies, to sustain the growth of this momentum.

\section{Acknowledgements}

None.

\section{Footnote}

Conflicts of Interest: The authors have no conflicts of interest to declare.

\section{References}

1. Jemal A, Siegel R, Ward E, et al. Cancer statistics, 2008. CA Cancer J Clin 2008;58:71-96.

2. Choti MA, Sitzmann JV, Tiburi MF, et al. Trends in long-term survival following liver resection for hepatic colorectal metastases. Ann Surg 2002;235:759-66.

3. Abdalla EK, Vauthey JN, Ellis LM, et al. Recurrence and outcomes following hepatic resection, radiofrequency ablation, and combined resection/ablation for colorectal liver metastases. Ann Surg 2004;239:818-25; discussion 825-7.

4. Fahy BN, D'angelica M, Dematteo RP, et al. Synchronous hepatic metastases from colon cancer: changing treatment strategies and results of surgical intervention. Ann Surg Oncol 2009;16:361-70.

5. Ratti F, Catena M, Di Palo S, et al. Impact of totally laparoscopic combined management of colorectal cancer with synchronous hepatic metastases on severity of complications: a propensity-score-based analysis. Surg Endosc 2016;30:4934-45.

6. Lyass S, Zamir G, Matot I, et al. Combined colon and hepatic resection for synchronous colorectal liver metastases. J Surg Oncol 2001;78:17-21.

7. Martin R, Paty P, Fong Y, et al. Simultaneous liver and colorectal resections are safe for synchronous colorectal liver metastasis. J Am Coll Surg 2003;197:233-41; discussion 241-2.

8. WeberJC, Bachellier P, Oussoultzoglou E, et al. Simultaneous resection of colorectal primary tumour and synchronous liver metastases. Br J Surg 2003;90:956-62.

9. Vogt P, Raab R, Ringe B, et al. Resection of synchronous liver metastases from colorectal cancer. World J Surg 1991;15:62-7.

10. Scheele J, Stang R, Altendorf-Hofmann A, et al. Resection 
of colorectal liver metastases. World J Surg 1995;19:59-71.

11. Ekberg H, Tranberg KG, Andersson R, et al. Determinants of survival in liver resection for colorectal secondaries. Br J Surg 1986;73:727-31.

12. Fong Y, Fortner J, Sun RL, et al. Clinical score for predicting recurrence after hepatic resection for metastatic colorectal cancer: analysis of 1001 consecutive cases. Ann Surg 1999;230:309-18; discussion 318-21.

13. Fuhrman GM, Curley SA, Hohn DC, et al. Improved survival after resection of colorectal liver metastases. Ann Surg Oncol 1995;2:537-41.

14. Yan TD, Chu F, Black D, et al. Synchronous resection of colorectal primary cancer and liver metastases. World J Surg 2007;31:1496-501.

15. Turrini O, Viret F, Guiramand J, et al. Strategies for the treatment of synchronous liver metastasis. Eur J Surg Oncol 2007;33:735-40.

16. Tanaka K, Shimada H, Matsuo K, et al. Outcome

doi: 10.21037/ales.2017.06.02

Cite this article as: Cheung TT, Un S. Emerging evidence of superior performance in laparoscopic combined hepatectomy and colectomy. Ann Laparosc Endosc Surg 2017;2:110. after simultaneous colorectal and hepatic resection for colorectal cancer with synchronous metastases. Surgery 2004;136:650-9.

17. van der Pool AE, Lalmahomed ZS, Ozbay Y, et al. 'Staged' liver resection in synchronous and metachronous colorectal hepatic metastases: differences in clinicopathological features and outcome. Colorectal Dis 2010;12:e229-35.

18. Thelen A, Jonas S, Benckert C, et al. Simultaneous versus staged liver resection of synchronous liver metastases from colorectal cancer. Int J Colorectal Dis 2007;22:1269-76.

19. Reddy SK, Pawlik TM, Zorzi D, et al. Simultaneous resections of colorectal cancer and synchronous liver metastases: a multi-institutional analysis. Ann Surg Oncol 2007;14:3481-91.

20. She WH, Chan AC, Poon RT, et al. Defining an optimal surgical strategy for synchronous colorectal liver metastases: staged versus simultaneous resection? ANZ J Surg 2015;85:829-33. 